\title{
Ergonomic Evaluation of Some University Laboratories
}

\author{
Yun Keun Lee ${ }^{1}$, Ik Mo Lee ${ }^{2}$, Jeongim Park ${ }^{3}$, Chung Sik Yoon ${ }^{4}, K_{w a n g}$ Won Rhie ${ }^{5}$, Hee Sok Park ${ }^{6}$ \\ ${ }^{1}$ Wonjin Institute for Occupational and Environmental Health, Seoul, 131-831 \\ ${ }^{2}$ Department of Chemistry, Inha University, Incheon, 402-751 \\ ${ }^{3}$ Department of Environmental Health Science, Soonchunhyang University, Asan, 336-745 \\ ${ }^{4}$ School of Public Health, Seoul National University, Seoul, 151-742 \\ ${ }^{5}$ Department of Safety Health Engineering, Hoseo University, Cheonan, 336-795 \\ ${ }^{6}$ Department of Industrial Engineering, Hongik University, Seoul, 121-791
}

\begin{abstract}
Objective: This article aims to report the results of ergonomic evaluation of some university laboratories. Background: Laboratory researchers are at risk for musculoskeletal injuries during routine laboratory procedures. However, little attention has paid to the working conditions of laboratory researchers, especially in Korea. Method: A checklist and questionnaire was developed and used to analyze the work conditions of 27 laboratories of chemistry, biology and pharmacy. Results: It was found that glove box, clean bench, and computer workstation are better than microscopy, and fume hood tasks, from ergonomic point of view. Conclusion: No domestic guideline is available for ergonomic intervention of laboratories. Further attention and studies are anticipated to improve the working conditions of laboratories.
\end{abstract}

Keywords: Laboratory, Checklist, Musculoskeletal disorders

\section{Introduction}

반복적인 동작과 불편한 작업자세, 힘쓰기, 접촉 스트레스, 진동 등과 같은 요인에 의해 발생하는 작업관련성 근골격계 질환은 국내외적으로 산업보건의 가장 중요한 문제 중의 하 나이다. 우리나라에서 근골격계질환은 전체 업무상 질병 환 자의 60 70\%를 차지할 정도로 심각한 실정이다(Ministry of Employment and Labor, 2012a).

다양한 업종에 종사하는 작업자들을 대상으로 근골격계 질환의 유병률과 위험요소 등이 연구되어 왔으나(Jeong, 2010), 대학 또는 연구소의 실험실에서 연구를 수행하는 연구자들에 대한 관심은 상대적으로 적은 편이다. 실험실 연구자들에서 발생하는 근골격계질환은 주로 손목과 손가
락, 팔꿈치, 어깨, 허리 부위에 나타나는 건염 및 건초염, 방아쇠 수지증, 근막통증후군, 요통 등이 대표적인 질환이며 (Fredriksson, 1995), 실험실에서 보고되는 재해의 65\% 이상이 근골격계질환이라고 보고된 바 있다(Caskey, 1999). 특히, 피펫팅 (pipetting) 작업은 엄지손가락에 가해지는 지 속적인 힘, 분당 수 십 회 이상의 반복성, 손목 및 어깨의 부적절한 작업자세로 인하여 가장 대표적인 위험 작업으로 여겨진다(Bjorksten et al., 1994; Raschke et al., 2005). 그리고 피펫 등의 실험기구를 이용한 연구과정은 대부분이 실험대(work bench)나 흠후드(fume hood), 클린벤치 (clean bench) 등에서 이루어진다. 이 과정에서 손목 및 손가락의 반복 사용, 목 및 허리 숙이기 자세가 신체에 지속적인 스트 레스를 주며, 대부분 작업면의 높이가 너무 높거나 낮아서 발생하는 현상이다(Asundi et al., 2005).

Corresponding Author: Yun Keun Lee. Wonjin Institute for Occupational and Environmental Health, Seoul, 131-831.

Phone: +82-2-490-4140, E-mail: lyk4140@hanmail.net

Copyright@2013 by Ergonomics Society of Korea(pISSN:1229-1684 eISSN:2093-8462). All right reserved.

(CC)This is an open-access article distributed under the terms of the Creative Commons Attribution Non-Commercial License(http://creativecommons.org/licenses/by-nc/3.0/), which permits unrestricted non-commercial use, distribution, and reproduction in any medium, provided the original work is properly cited. http://www.esk.or.kr 
하지만 외국에 비하여 국내에서 실험실 연구자에 대한 인 간공학 분야의 관심은 더욱 미미하여, 인간공학적 측면에서 작업조건, 실험도구 및 장비, 작업자세 등에 어떤 문제가 있 는지에 대하여 보고된 적이 없다. 이에 본 연구에서는 일부 대학교 실험실을 대상으로 인간공학적 평가를 실시하고, 문 제점에 대한 관리 방향을 제시하고자 한다.

\section{Method}

선행 연구(Raschke et al., 2005)에서 가장 사용 빈도가 높은 장비로 보고된 실험대, 흠후드, 클린벤치, 글러브박스, 현미경 작업대, 컴퓨터 작업대, 피펫 등을 연구대상으로 선 정하였다. 이러한 실험장비를 많이 사용하는 실험실을 선정 하기 위하여 9 개 실험실을 대상으로 예비 조사를 실시하였 다. 그 결과 사용 빈도가 높은 실험실로서 화학, 생물, 생명, 약학, 환경 관련 실험실을 평가대상으로 결정하였고, 서울, 인천, 천안에 소재한 3 개 대학교의 총 27 개 실험실(화학 14 개, 생물/생명 9개, 약학/환경 4개)을 평가하였다. 평가대 상 실험장비는 Table 1 과 같다.

Table 1. The equipment analyzed in the study

\begin{tabular}{c|c}
\hline Equipment & $\mathrm{n}$ \\
\hline Computer workstation & 60 \\
\hline Work bench & 48 \\
\hline Pipette & 41 \\
\hline Fume hood & 21 \\
\hline Microscopy bench & 15 \\
\hline Clean bench & 14 \\
\hline Glove box & 12 \\
\hline Total & 211 \\
\hline
\end{tabular}

실험장비에 대한 인간공학적 평가는 연구진이 개발한 체 크리스트를 이용하여 비디오 분석과 실측을 통해 이루어졌 다. 평가 항목으로는 작업점의 높이, 다리를 뻗을 수 있는
공간 $(55 \mathrm{~cm}$ 이상), 아래팔 지지공간 $(15 \mathrm{~cm}$ 이상), 아래팔 접촉면 상태(접촉면에 의한 압박 유무), 허리의 자세(20도 이상 굴곡), 의자 좌면 높이, 의자 등받이 유무, 규칙적인 휴 식시간 유무, 1 일 연속작업시간(2시간 이내) 등을 평가하 였다.

각 장비의 치수는 직접 실측하였고, 소음과 피펫을 사용할 때 문제되는 손가락 누르기 동작은 각각 소음측정기와 푸시 -풀 게이지(push-pull gauge)를 이용하여 측정하였다.

또한 설문지를 이용하여 실험시간 등 작업조건과 연구자 들의 인구학적 특성을 조사하였다. 설문에 참여한 연구원은 총 209명으로 남자가 $62.2 \%$ 였고, 평균 연령은 26.5세로 20 대가 대부분이었다 $(86.6 \%)$. 실험실 경력은 2 년차 이상이 $77 \%$ 였으며, 평균 경력은 32개월이었고, 석사과정이 $61.7 \%$, 박사과정이 $38.3 \%$ 였다.

\section{Results}

\subsection{Working hours}

주요 실험종류에 대하여 1 일 평균 실험시간을 설문 조사 한 결과, 흄후드 사용(1일 평균 147분)과 피펫 사용시간 (146분)이 가장 많은 것으로 나타났다. 그 외 클린벤치, 글 러브박스, 현미경 사용과 관련된 실험시간은 상대적으로 적 었다(Table 2). 전공별로는 생명공학 관련 실험실은 피펫과 글러브박스 및 현미경 사용 실험이 상대적으로 높게 나타났 으며, 화학공학 관련 실험실은 흠후드 사용, 피펫 사용이 상 대적으로 많은 것으로 나타났다(Table 3).

\subsection{Working conditions}

\subsubsection{Computer workstation}

조사된 개인용 책상의 평균 높이는 $752 \mathrm{~mm}$ 로서 대부분이 고용노동부에서 권고(Ministry of Employment and Labor, 2012b)하고 있는 컴퓨터 작업용 책상의 적정 높이(600 $700 \mathrm{~mm}$ ) 보다 높은 것을 사용하고 있었다. 실제 작업자세를 관찰한 결과, 대상자의 $42.7 \%$ 가 적정 높이보다 높은 위치에 키보드를 올려놓고 컴퓨터 작업을 하고 있었다. 이로 인하여

Table 2. Work pattern (mean(SD))

\begin{tabular}{c|c|c|c|c|c|c}
\hline Type & Fume hood & Pipette & Clean bench & Glove box & Microscopy & Cleaning \\
\hline Number of responses & 156 & 167 & 62 & 54 & 77 & 187 \\
\hline Average days of work per week & $4.5(1.6)$ & $4.5(1.5)$ & $4.7(2.1)$ & $2.8(1.3)$ & $3.2(1.9)$ & $5.4(5.7)$ \\
\hline Average work period per day(minute) & $147.3(117.2)$ & $146.0(114.3)$ & $87.5(68.5)$ & $70.6(64.3)$ & $69.3(66.7)$ & $63.9(56.0)$ \\
\hline
\end{tabular}


Table 3. Work pattern by discipline(minute)

\begin{tabular}{c|c|c|c|c|c|c|c}
\hline Laboratory & $\mathrm{n}$ & Fume hood & Pipette & Clean bench & Glove box & Microscopy & Cleaning \\
\hline Biology & 40 & 47.4 & 160.3 & 84.2 & 128.6 & 80.9 & 47.2 \\
\hline Chemistry & 125 & 177.8 & 150.5 & 82.5 & 55.0 & 66.1 & 72.2 \\
\hline Pharmacy & 44 & 44.1 & 109.2 & 101.5 & 84.5 & 60.0 & 54.0 \\
\hline Total & 209 & 147.3 & 146.0 & 87.5 & 70.6 & 69.3 & 63.9 \\
\hline
\end{tabular}

어깨가 들리는 현상이 발생하며, 어깨와 손목 부위의 통증을 초래할 수 있다. 또한 조사 대상자의 $56.7 \%$ 가 앉은오금높이 보다 높은 의자를 사용하고 있었으며, 이는 높은 작업면 높 이에 맞추기 위해 의자 높이를 올려서 사용하기 때문이다, 그 외, 책상 위 아래팔 지지공간 $(15 \mathrm{~cm}$ 이상), 책상 밑 다리 공간, 마우스 위치 등은 적정 기준을 만족하는 것으로 나타 났다(Table 4).

Table 4. Results of ergonomic evaluation of computer workstations $(n=60)$

\begin{tabular}{l|c|c}
\hline Factor & Yes $(\%)$ & No(\%) \\
\hline Adjustable desk(or keyboard) height & 0 & 100.0 \\
\hline Proper desk(or keyboard) height & 58.3 & 42.7 \\
\hline Reduced contact pressure at desk edge & 53.3 & 46.7 \\
\hline $\begin{array}{l}\text { Proper room for lower arm support } \\
(>15 \mathrm{~cm})\end{array}$ & 93.3 & 6.7 \\
\hline Proper room over desk & 33.3 & 66.7 \\
\hline Proper leg room & 80.0 & 20.0 \\
\hline Proper position/height of mouse & 93.3 & 6.7 \\
\hline Adjustable chair height & 73.3 & 26.7 \\
\hline Proper chair height & 43.3 & 56.7 \\
\hline Chair with seat back & 100.0 & 0 \\
\hline Proper seat back & 56.7 & 43.3 \\
\hline Stable seat pan & 73.3 & 26.7 \\
\hline Proper distance between eyes and screen & 46.7 & 53.3 \\
\hline Proper screen height(eye level) & 80.0 & 20.0 \\
\hline Work duration per day(<4 hour) & 40.0 & 60.0 \\
\hline Periodic rest break & 33.3 & 66.7 \\
\hline Average & 59.9 & 40.1 \\
\hline & & \\
\hline
\end{tabular}

\subsubsection{Workbench and chair}

사용 빈도가 가장 많은 실험대 높이는 평균 800(793 812) $\mathrm{mm}$ 로 측정되었다. 이 조건 하에서 작업자세를 관찰한 결과, 조사 대상자의 $89.6 \%$ 가 목을 과도하게 숙이거나 위팔
이 45 도 이상 몸통에서 벗어나는 등 높이가 부적절한 것으 로 나타났다(Figure 1). 즉, 앉아서 실험하는 경우에는 현재 의 실험대가 너무 높아 의자를 최대한 높여서 사용하지 않으 면 어깨가 들리는 현상이 발생한다. 반면 서서 실험하는 경 우에는 실험대가 낮아서 허리와 목을 숙여야 한다. 또한 실 험대 밑에 다리를 뻗을 수 있는 공간이 있는 경우는 $18.9 \%$ 에 불과하였다. 따라서 의자에 앉아서 실험할 때는 실험대 밑에 다리를 뻗을 수 없으므로 상체를 작업대에 가까이 하기 위해서 허리를 등받이에 기댈 수가 없는 불편함이 발생하게 된다. 또한 대부분이 의자에 앉았을 때 뒤꿈치가 들리는 높 은 의자를 사용 $(88.4 \%)$ 하고 있었으며, 실험대 위의 아래팔 지지공간이 부적절하거나 $62.5 \%)$, 실험대 가장자리가 아래 팔을 압박하는 현상 $(100 \%)$ 이 발생하였다(Table 5).

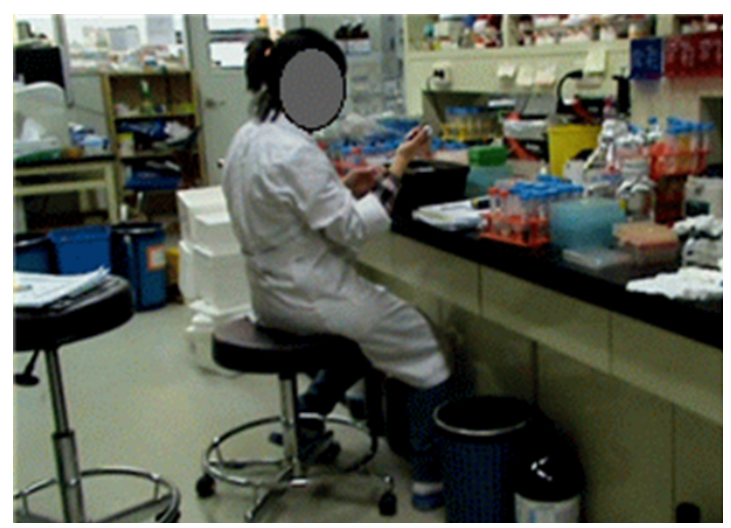

Figure 1. Work bench

Table 5. Results of ergonomic evaluation of work benches $(n=48)$

\begin{tabular}{l|c|c}
\hline Factor & Yes $(\%)$ & No(\%) \\
\hline Reduced contact pressure at bench edge & 0 & 100.0 \\
\hline Proper room for lower arm support & 37.5 & 62.5 \\
\hline Proper leg room & 18.9 & 81.1 \\
\hline Proper bench height & 10.4 & 89.6 \\
\hline
\end{tabular}


Table 5. Results of ergonomic evaluation of work benches $(n=48)$ (Continued)

\begin{tabular}{l|c|c}
\hline Factor & Yes(\%) & No(\%) \\
\hline $\begin{array}{l}\text { Less than 2 hour work per day at } \\
\text { fixed position }\end{array}$ & 80.0 & 20.0 \\
\hline Adjustable chair height & 37.5 & 62.5 \\
\hline Proper chair height & 11.6 & 88.4 \\
\hline Chair with seat back & 69.7 & 30.4 \\
\hline Proper seat back & 58.2 & 41.8 \\
\hline Stable seat pan & 69.8 & 30.2 \\
\hline Average & 39.4 & 60.6 \\
\hline
\end{tabular}

\subsubsection{Fume Hood}

홈후드의 평균 높이는 실험대 보다 더 높은 844(775 917) $\mathrm{mm}$ 로 측정되었다. 따라서 실험대와 마찬가지로 서서 실험하기에는 너무 낮아 허리와 목을 숙여야 하고(Figure 2), 앉아서 실험하기에 너무 높아 상완이 위로 들리는 현상 이 발생한다. 또한 다리를 뻗을 수 있는 공간과 아래팔을 지 지할 수 있는 여유공간이 있는 경우는 전혀 없었다. 이러한 문제점으로 인해 특히 목과 허리 부위의 작업자세가 부적절 한 것으로 나타났다. 그 외 조사 대상자의 $53.2 \%$ 가 소음으 로 인한 불편함을 호소하였다(Table 6).

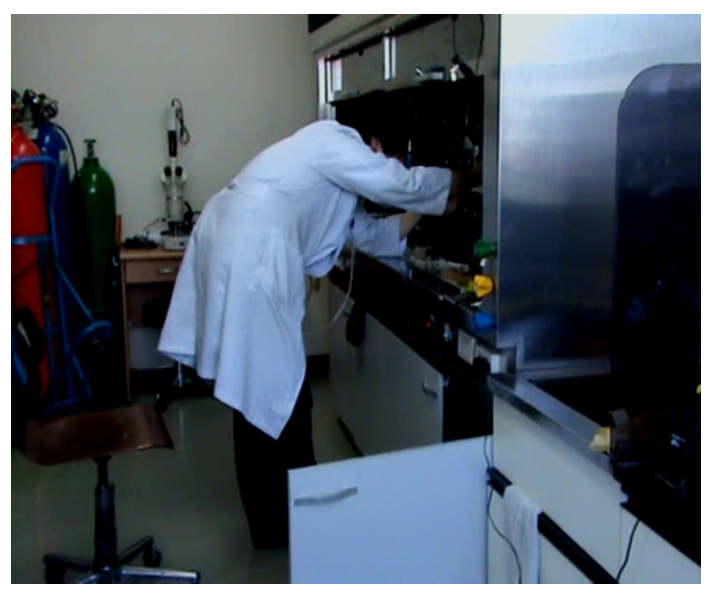

Figure 2. Fume hood

\subsubsection{Microscopy}

현미경 작업대 또한 흠후드와 마찬가지로 아래팔 지지공 간과 다리를 뻗을 수 있는 공간이 없었으며 $(100 \%)$, 접안렌 즈 조절이 불가능하였고 $(80 \%)$, 책상 선단에 아래팔이 지속
Table 6. Results of ergonomic evaluation of fume hood( $\mathrm{n}=21)$

\begin{tabular}{l|c|c}
\hline Factor & Yes(\%) & No(\%) \\
\hline Sedentary work possible & 23.8 & 76.2 \\
\hline Reduced contact pressure at bench edge & 33.3 & 66.7 \\
\hline Proper room for lower arm support & 0 & 100.0 \\
\hline Proper leg room & 0 & 100.0 \\
\hline No discomfort by glare & 57.1 & 42.9 \\
\hline No discomfort by noise & 42.8 & 53.2 \\
\hline Proper back posture & 33.3 & 66.7 \\
\hline Proper neck posture & 23.8 & 76.2 \\
\hline Proper bench height & 23.8 & 76.2 \\
\hline $\begin{array}{l}\text { Less than 2 hour work per day at } \\
\text { fixed position }\end{array}$ & 42.9 & 57.1 \\
\hline Average & 0.0 & 100.0 \\
\hline
\end{tabular}

적으로 압박되는 현상(80\%)이 발생하였다(Table 7). 이로 인해 작업자 대부분 $(100 \%)$ 이 목을 숙이는 부적절한 작업자 세를 취하고 있었다(Figure 3). 긴장된 상태에서 고정된 자 세를 유지하게 되면 근육 피로가 매우 빠르게 진행된다. 현 미경 관찰 작업은 대부분이 정적인 상태에서 작업이 이루어 지며 따라서 목과 어깨 부위가 매우 긴장된 상태가 지속될 수밖에 없다.

Table 7. Results of ergonomic evaluation of microscopy work $(\mathrm{n}=15)$

\begin{tabular}{l|c|c}
\hline Factor & Yes $(\%)$ & No(\%) \\
\hline Adjustable bench height & 0 & 100.0 \\
\hline Reduced contact pressure at bench edge & 20.0 & 80.0 \\
\hline Proper leg room & 0 & 100.0 \\
\hline Proper room for lower arm support & 0 & 100.0 \\
\hline Adjustable height of lenses & 20.0 & 80.0 \\
\hline Sedentary work possible & 53.3 & 46.7 \\
\hline $\begin{array}{l}\text { Flexible position of chair } \\
\text { (close to bench) }\end{array}$ & 46.7 & 53.3 \\
\hline Chair with seat back & 66.7 & 33.3 \\
\hline Proper neck posture & 0 & 100.0 \\
\hline Proper shoulder posture & 66.7 & 33.3 \\
\hline $\begin{array}{l}\text { Less than 2 hour work per day at } \\
\text { fixed position }\end{array}$ & 100.0 & 0 \\
\hline Periodic rest break & 0 & 100.0 \\
\hline Average & 31.1 & 68.9 \\
\hline
\end{tabular}




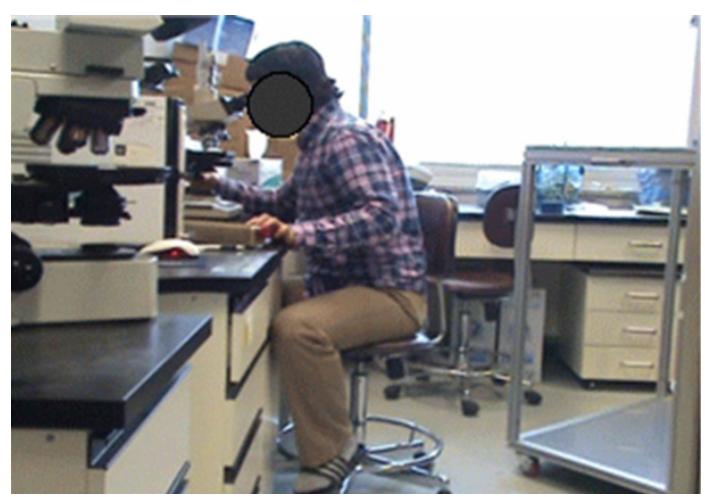

Figure 3. Microscopy

\subsubsection{Clean Bench}

클린벤치의 작업면 높이는 평균 $765(745 ~ 842) \mathrm{mm}$ 로 흠 후드 및 실험대 보다는 상대적으로 낮았고, 의자에 앉을 수 있는 조건이었다. 그러나 다리를 뻗을 수 있는 공간이 부족 했으며 $(64.3 \%)$, 흠후드와 마찬가지로 아래팔 지지공간이 없는 경우가 많았다(50.0\%) (Table 8). 이로 인해 목 부위 작업자세가 대부분 부적절하였다 $(85.7 \%$ ) (Figure 4$)$.

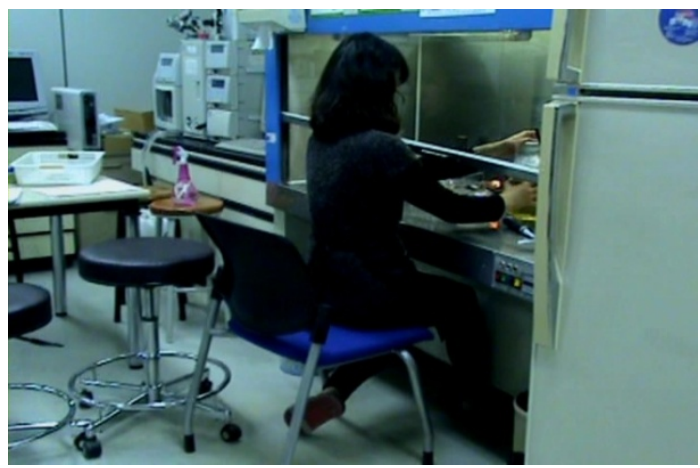

Figure 4. Clean bench

Table 8. Results of ergonomic evaluation of clean bench $(n=14)$

\begin{tabular}{l|c|c}
\hline Factor & Yes $(\%)$ & No(\%) \\
\hline Sedentary work possible & 100.0 & 0 \\
\hline Reduced contact pressure at bench edge & 100.0 & 0 \\
\hline Proper room for lower arm support & 50.0 & 50.0 \\
\hline Proper leg room & 35.7 & 64.3 \\
\hline No discomfort by glare & 50.0 & 50.0 \\
\hline No discomfort by noise & 50.0 & 50.0 \\
\hline Proper back posture & 71.4 & 28.6 \\
\hline
\end{tabular}

Table 8. Results of ergonomic evaluation of clean bench( $n=14)$ (Continued)

\begin{tabular}{l|c|c}
\hline Factor & Yes(\%) & No(\%) \\
\hline Proper neck posture & 14.3 & 85.7 \\
\hline Proper work height & 85.8 & 14.2 \\
\hline $\begin{array}{l}\text { Less than 2 hour work per day at } \\
\text { fixed position }\end{array}$ & 50.0 & 50.0 \\
\hline Average & 60.7 & 39.3 \\
\hline
\end{tabular}

\subsubsection{Glove Box}

글러브박스의 작업 높이는 비교적 양호한 것으로 평가되 었다. 그러나 정해진 위치에 오랫동안 정적인 자세로 서 있 는 상태 $(100 \%)$ 와 소음으로 인한 불편함 $(75 \%)$ 이 큰 것으 로 나타났다(Table 9) (Figure 5). 실험자의 귀 높이에서 소음을 측정한 결과 평균 $73.0(69.8 \sim 76.2) \mathrm{dB}$ 로 흠후드 $(69 \mathrm{~dB})$ 나 클린벤치 $(68 \mathrm{~dB})$ 에 비해 상대적으로 높게 나타 났다.

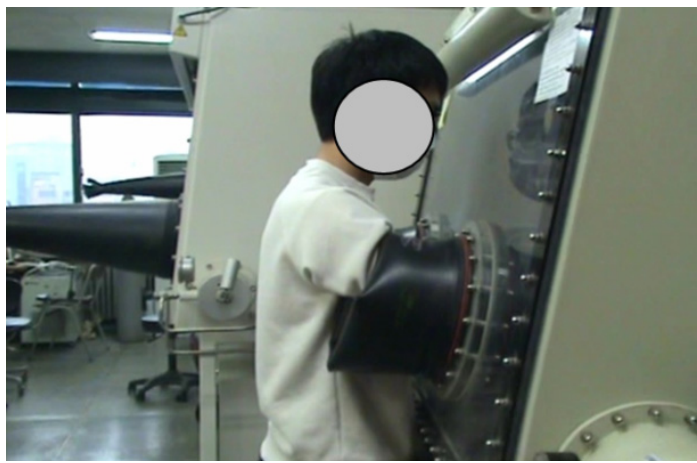

Figure 5. Glove box

Table 9. Results of ergonomic evaluation of glove box $(\mathrm{n}=12)$

\begin{tabular}{l|c|c}
\hline Factor & Yes $(\%)$ & No $(\%)$ \\
\hline Proper work height & 83.3 & 16.7 \\
\hline Proper back posture & 75.0 & 25.0 \\
\hline Proper neck posture & 75.0 & 25.0 \\
\hline No discomfort by noise & 25.0 & 75.0 \\
\hline No discomfort by glare & 75.0 & 25.0 \\
\hline Proper leg room & 100.0 & 0 \\
\hline Anti-fatigue mat & 0 & 100.0 \\
\hline $\begin{array}{l}\text { Less than 2 hour work per day } \\
\text { at fixed position }\end{array}$ & 100.0 & 0 \\
\hline Average & 66.7 & 33.3 \\
\hline
\end{tabular}




\subsubsection{Pipetting}

피펫 작업은 손가락의 누르는 힘을 반복적으로 사용하는 수동식 피펫 사용비율이 $26.8 \%$ 로 나타났다. 특히 수동식 피 펫의 경우 피펫팅을 할 때 엄지손가락을 반복적으로 누르게 되는데 이 때 누르는 힘이 평균 $1.2(0.5 \sim 4.0) \mathrm{kg}$ 으로서 다 소 높은 수준으로 여겨진다. 또한 피펫의 길이가 $257 \mathrm{~mm}$ 로 비교적 긴 편이어서 계량할 때 팔을 높이 들어야 하며 (Figure 6), 부적절한 작업면의 높이 $(70.8 \%)$ 와 손목의 부 적절한 작업자세 $(63.4 \%)$ 가 문제점이었다(Table 10).

피펫팅은 일반적인 실험실의 가장 대표적인 작업으로 세 포생물학 실험실의 경우 전체 실험시간의 57 88\% 정도가 피펫팅 작업에 해당될 정도로 빈번한 작업이다(Bjorksten et al., 1994). 피펫팅 시에 손가락 및 손목 부위는 분당 59 89회 정도의 반복적인 동작이 이루어지며, 손가락에 가 해지는 힘은 정밀성이 높을수록 $5 \%$ 정도의 부가적인 힘이 더 필요하고, 사용하는 용액의 점도에 따라 $11 \%$ 정도의 부

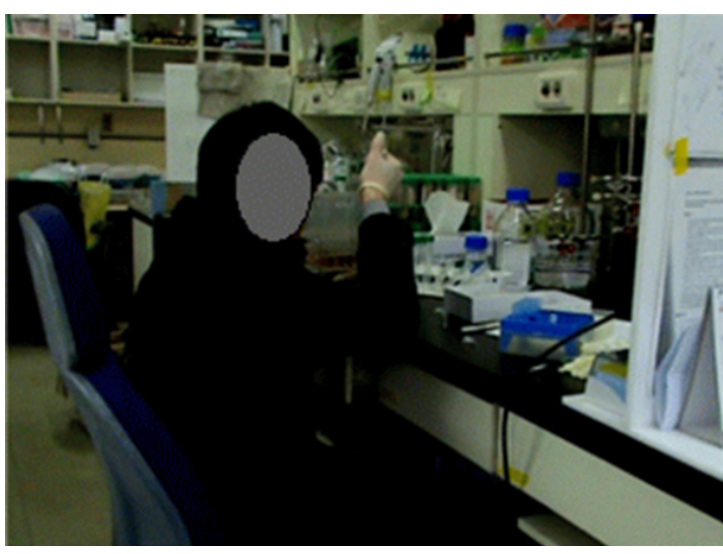

Figure 6. Pipetting

Table 10. Results of ergonomic evaluation of pipetting $(n=41)$

\begin{tabular}{l|c|c}
\hline Factor & Yes $(\%)$ & No(\%) \\
\hline Powered pipette used & 73.2 & 26.8 \\
\hline Proper pipette shape(grip) & 80.5 & 19.5 \\
\hline Proper finger pressure & 36.6 & 63.4 \\
\hline Proper wrist posture & 36.6 & 63.4 \\
\hline $\begin{array}{l}\text { Less than 2 hour work per day } \\
\text { at fixed position }\end{array}$ & 60.9 & 39.1 \\
\hline Proper work height & 29.2 & 70.8 \\
\hline Periodic rest break & 9.8 & 90.2 \\
\hline Average & 46.7 & 53.3 \\
\hline
\end{tabular}

가적인 힘이 더 필요한 것으로 알려져 있다(Asundi et al., 2005).

\section{Conclusions}

본 연구에서는 일부 대학교 실험실의 작업조건을 인간공 학적 관점에서 평가하였다. 1일 평균 실험시간을 보면 흠후 드 사용과 피펫 사용시간이 가장 많은 것으로 나타났으며, 주당 평균 실험 빈도(횟수)에서는 세척 작업과 피펫, 흠후드 를 사용하는 실험 빈도가 높은 것으로 나타났다. 인간공학적 측면에서 상대적으로 작업조건이 좋은 장비는 글러브박스, 클린벤치, 컴퓨터 작업대이었고, 현미경 작업 및 흠후드 사 용 작업이 가장 열악한 작업조건으로 평가되었다. 특히 흠후 드 사용 작업은 가장 실험빈도가 많은 장비로 주된 문제가 작업 높이와 아래팔 지지공간, 다리를 뻗을 있는 조건 등이 가장 큰 문제로 평가되어 시급히 개선되어야 할 것이다.

장비들은 부적절한 높이와 의자에 앉은 상태에서 다리를 뻗을 수 없는 구조적 한계들을 가지고 있다. 작업대의 위치 가 너무 높게 되면 상완의 외전이 커져서 삼각근에 부담을 주거나 어깨가 너무 올라가게 되어 어깨 부위가 쉽게 피로해 진다. 반대로 작업점의 높이가 너무 낮으면 목과 허리를 숙 이게 되고 이러한 정적인 작업자세가 지속되면 목과 허리 부위의 통증의 원인이 된다. 실험실의 작업 특성은 특정한 작업자세를 수분 이상 정적인 상태로 유지한다는 특징이 있 다. 따라서 실험자의 인체치수에 맞지 않는 부적절한 인간공 학적 조건(특히 높이)에서 장기간 동안 작업이 이루어진다 면 근골격계질환의 원인이 될 수 있다.

본 연구에서는 주로 실험대의 높이와 관련된 분석에 치중 하였으나, 추후 반복성을 포함한 보다 다양한 인간공학적 요 인과 주관적인 불편감에 대한 포괄적인 분석이 요구된다.

인간공학적으로 부적절한 책상 및 의자, 기타 작업도구에 대한 연구는 여러 작업을 대상으로 그 동안 많은 연구들이 진행되어 왔다. 특히 컴퓨터 작업자의 인간공학적 표준관리 지침은 여러 국가 및 국제기관에서 인간공학적 기준을 제정 하여 시행해오고 있다. 그러나 실험실의 인간공학적 문제는 제조업 및 사무 환경과는 달리 여전히 사각지대에 놓여 있고, 실험실에서의 인간공학적 표준은 없는 실정이다. 국제기준에 실험실 관련 표준(ISO 8655-1 6:2002-2007)이 있으나 이는 피펫 제조자나 피펫 보정을 위한 서비스 제공자 및 사 용자가 준수해야 할 국제 표준이다. 또한 미국 정부에서도 실험실의 안전보건 기준을 정하고 있으나, 이는 화학물질로 인한 건강장해와 사고 예방이 주 목적이다. 우리나라도 한국 산업안전보건공단이 발간한 실험실 안전보건에 관한 기술지 
침(KOSHA Code G-7-2006) 와 교육과학기술부의 실험실 안전관리매뉴얼이 있으나, 이 역시 실험실 내 안전관리를 목 적으로 규정하고 있다. 따라서 장기적으로는 실험장비의 설 계지침을 포함한 실험실의 인간공학적 표준이 만들어져야 하고, 이러한 지침을 만들 때는 우리나라 국민의 크기에 맞 는 실험장비에 대한 연구가 선행되어야 한다.

\section{Acknowledgements}

This research was supported by the National Research Foundation of Korea (NRF) grant funded by the Korea government (No 2010-0029174).

\section{References}

Asundi, K.R., Bach J.M. and Rempel, D.M., Thumb force and muscle loads are influenced by the design of a mechanical pipette and by pipetting tasks, Human Factors, 20(1), 67-76, 2005.

Bjorksten, M.G., Almby, B. and Jansson, E.S., Hand and shoulder ailments among laboratory technicians using modern plunger operated pipettes, Applied Ergonomics, 25(2), 88-94, 1994.

Caskey, C.R., Ergonomics in the clinical laboratory, Clinical Laboratory Science, 12(3), 140-144, 1999.

Fredriksson, K., Laboratory work with automatic pipettes: a study on how pipetting affects the thumb, Ergonomics, 38(5), 1067-1073, 1995.

Jeong, B.Y., Ergonomics role for preventing musculoskeletal Disorders, Journal of the Ergonomics Society of Korea, 29(4), 393-404, 2010.

Ministry of Employment and Labor, Analysis of Industrial Accidents of 2011, 2012a.

Ministry of Employment and Labor, Guide on VDT work, Official announcement 2012-72, 2012b.

Raschke, S.U., Birch, G. and Mattie, J.M., Evaluation of best practices for alleviating and preventing cumulative trauma disorder amongst healthcare laboratory technologist involved in pipetting work, Occupational Health \& Safety Agency for Healthcare in British Columbia, Canada, 2005.

\section{Author listings}

Yun Keun Lee: lyk4140@hanmail.net

Highest degree: $\mathrm{PhD}$, Department of Public Health, Graduate School, Catholic University

Position title: Aassociate Director, Wonjin Institute for Occupational and Environmental Health

Areas of interest: Musculoskeletal disorders, Risk assessment

Ik Mo Lee: imlee@inha.ac.kr

Highest degree: $\mathrm{PhD}$, Department of Chemistry, Ohio State University Position title: Professor, Department of Chemistry, Inha University Areas of interest: Laboratory Safety System and Education, Assessment of Hazard Chemicals

Jeongim Park: jeongim@sch.ac.kr

Highest degree: $\mathrm{PhD}$, School of Public Health, University of Michigan Position title: Assistant Professor, Soonchunhyang University

Areas of interest: Exposure assessment in occupational settings

Chungsik Yoon: csyoon21c@yahoo.com

Highest degree: $\mathrm{PhD}$, School of Public Health, Seoul National University Position title: Professor, School of Public Health, Seoul National

University

Areas of interest: Occupational health

Kwang Won Rhie: kwrhie@hoseo.edu

Highest degree: $\mathrm{PhD}$, Technical University of Berlin

Position title: Professor, Department of safety health engineering, Hoseo University

Areas of interest: Occupational accident

Hee Sok Park: hspark@hongik.ac.kr

Highest degree: $\mathrm{PhD}$, Department of Industrial and Operations Engineering, The University of Michigan

Position title: Professor, Department of Industrial Engineering, Hongik University

Areas of interest: Occupational ergonomics, Musculoskeletal disorders

Date Received : 2013-05-09

Date Revised : 2013-07-25

Date Accepted : 2013-07-30 